\title{
Standard Maintenance Practice for Feed Pellet Operation
}

\author{
Sreenivasa Rao Pagolu* \\ Assistant General Manager, Department of Production, Maintenance and Utilities, BMR Industries Pvt. Ltd, \\ Nellore, India \\ *Corresponding author: srpagolu@gmail.com
}

\begin{abstract}
Plant Engineering, Maintenance, Repair and over hauling are most important in manufacturing industries. The aim of this paper is to identify and suggest good standard maintenance practice for feed milling operation in an animal feed manufacturing unit. It derives various results based on practical implementation in feed mill operation and data provided are an actual drawn in feed mill in a feed manufacturing industry. The outcome is discussed and studied in compare with standard maintenance practices.
\end{abstract}

Keywords: Effectiveness, Feed, Mill, Pellet, Scraper.

\section{Introduction}

The standard maintenance practices for feed pellet operations are derived from practical operations find in a feed mill manufacturing. The factors are considered are as follows.

a) Preventive maintenance - effectiveness.

b) Preventive maintenance structure.

c) History cards and Equipment data.

d) Breakdown Maintenance reports.

e) Spare part management.

f) Procedure for pre-requisites for maintenance.

g) Analysis of breakdown (To eliminate the failure permanently).

\section{Factors}

\section{A. Preventive Maintenance - Effectiveness}

The preventive maintenance plans are to be derived based on standard procedure given by supplier along with equipment and to be modified time to time based on breakdown history. The effectiveness of preventive maintenance to be monitored time to time. It may draw from breakdown history. If the break down history indicates that the specific break down repeats again and again shows that the preventive maintenance is not effective, it needs modification in the schedule or needs analysis for root cause for failure. Here, we may consider any one of the suitable root cause analysis tool.

- $\quad$ PDCA (Plan-Do- Check-Act).

- $8 \mathrm{D}$ approach.

- Why - Why Analysis.

- Cause - Effective Diagram.
- Pareto Chart.

\section{B. Preventive Maintenance Structure}

The preventive maintenance structure may be drawn by considering history of equipment as well as standard procedure. During consideration of history, major breakdowns which are taking much time to repair as well as the spares cost and production cost (Loss of production and its implication in production as well as difficulties in dispatch) are to be considered. The schedule should be such a way that the production loss should be nil. Most of the time it will be planned on non-production days or weekly off days to eliminate production loss. It should draw total schedule once in year and may update time to time based on production plans. If feed pellet operations, there are specific seasons where operation of mills will be minimum like winter and continues operation in summer season. By considering seasonal advantage, the maintenance team may draw their preventive maintenance plans accordingly, so that the production loss will be eliminated. One important factor is; we need to consider is Brain Storming with maintenance team as well as pellet mill operators. Most of the time pellet mill operators are tends to adjust various operational parameters like steam, mash flow, roller gaps, temperature, in-scraper, out-scraper etc... and another factor is who has to attend preventive maintenance? Here, we need to consider,

1. Objective of preventive maintenance.

2. Technician skill set.

3. Supervisor skill set.

4. What parts are to be repaired?

5. What parts are to be replaced?

6. How much time it needs to complete preventive maintenance?

7. Updating of documents.

8. Recommendations for next preventive maintenance.

\section{History Cards and Equipment Data}

Equipment data of pellet mill to be recorded as follows:

1. Make

2. Model

3. Capacity in Tons /Hr.

4. Motor Make 
5. Motor KW /HP

6. Motor Bearing Data

7. Motor Seals

8. Shaft data

9. Die sizes

10. Roller sizes

11. Bearing sizes etc.

A typical pellet mill equipment data card is shown in fig 1 . and fig 2 .

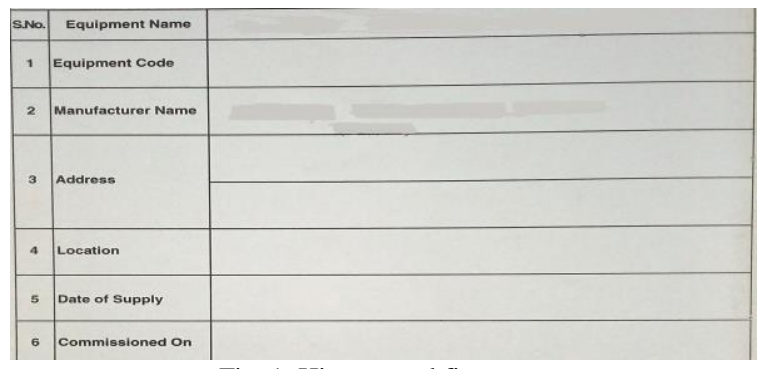

Fig. 1. History card first page

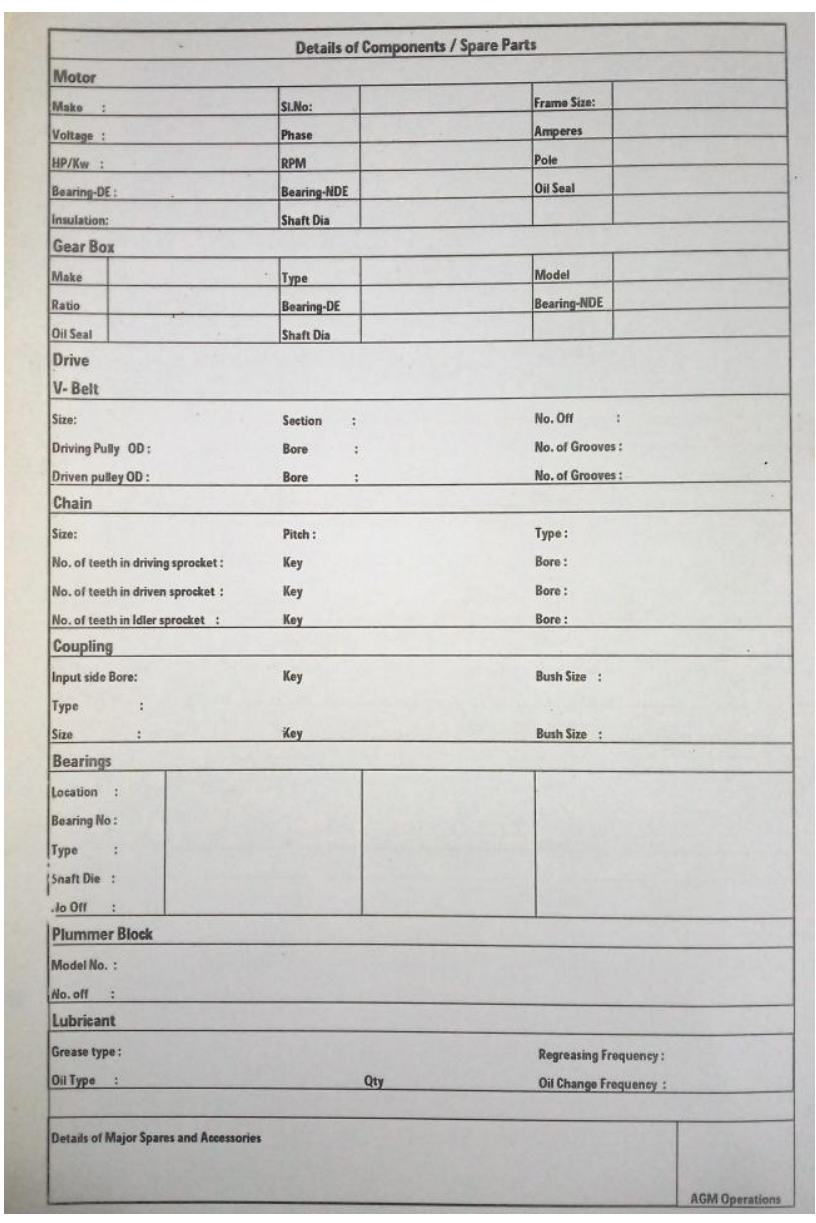

Fig. 2. History card second page

History of the pellet mill is to be recorded time to time which should include die size used, roller bearings replaced, bearing life, roller life, die life, shearing pin replaced and reason for replacement, whether the problem is found, root cause for failure of shear pin, pre-cautions or prevention for failure, die clamps replaced, spindle bearing condition, vibration analysis conducted and due next due for vibration analysis and its current conditions, recommendations for further etc. Along with pellet mill, die life record, roller life record, roller bearing records are to be maintained for transparent data analysis.

\section{Breakdown Maintenance Reports}

This will helpful to eliminate root cause for failure. Since pellet mill operation is critical for feed manufacturing, every parameter is to be recorded. The following parameters are to be recorded.

1. Which size Die is in operation, whether it is $1.0 \mathrm{~mm}$, $1.2 \mathrm{~mm}, 1.6 \mathrm{~mm}, 1.8 \mathrm{~mm}, 2.0 \mathrm{~mm}$ or $2.2 \mathrm{~mm}$ ?

2. What is the frequency? Is it reduced frequency or $50 \mathrm{~Hz}$ ? What is the reason for running feed mill with reduced frequency?

3. What is the gap between die and roller?

4. What is the color of the pellet during breakdown?

5. What is the Pre-conditioner temperature?

6. How much steam pressure?

7. How much Steam flow?

8. What is Single shaft conditioner flow rate?

9. What is double shaft conditioner flow rate?

10. Is it the temperature drop or increase is found during breakdown?

11.Is the breakdown is occurred during steam adjustment?

By recording the above data will helpful maintenance team to resolve breakdown as well as they may update their records.

\section{E. Spare Part Management}

This is critical for maintenance team to maintain spares for pellet mill. The two criteria's are to be considered, one is Cost of spares and second is lead time to procure. There is some critical spare which are to be maintained line Shear Pin, Roller bearings, scrapers etc., since there is low cost.

\section{F. Procedure for Pre-requisites for Maintenance}

The following issues are to be keep in mind during draw of procedure for pre-requisites.

1. "Cross contamination"

2. Skill set and Safety of technicians.

3. Required Tools.

4. Operation, maintenance and spare parts manual.

In brief detail, the "cross contamination to be avoided. Clean the surroundings before attending breakdown, keep the hands clean, make ready of tools and spares. Ensure the skill set of technician, use appropriate PPEs.

\section{G. Analysis of Breakdown (To eliminate the failure permanently)}

Make a practice to analyze the break down to eliminate permanently. Repeat breakdown create irritation for production team. Sometimes repeated minor breakdowns lead to irritation 
of the people, which is called irritants, which never be neglected. In feed mill operations small breakdowns lead to temperature losses which lead to rejection of feed.

\section{Standard Maintenance Practice (SMP) for Feed Pellet Operation}

- Receive break down slip from user department.

- Get the work permission for pellet mill from operational department and take line clearance from electrical department (put lock out tag out).

- Consider the work permit if required.

- Use appropriate PPE's.

- Ensure the emergency stop is in push / lock condition.

- Keep right tools ready.

- Keep the operation, maintenance and spare parts manual ready.

- Keep the expected spares ready to replace.

- Clean hands, tools and surroundings to avoid cross contamination.

- Attend breakdown.

- Report for record update immediately.

- Ensure that all safety barriers are in place, are secure and effectively protect people from accessing moving parts during operation.

- Check any material spillage /leakage.

- Clean the equipment thoroughly.
- Remove all tools and tackles from the workplace after completion of work and clear the line clearance and take trial run.

- Observe the performance of the machine during the trial run.

- Close the breakdown slip by obtaining signature from user department.

\section{Conclusion}

The feed operation and maintenance needs critical skill set. The standard maintenance practice for feed pellet operation helps maintenance team to maintain feed pellet mills to reduce maintenance time, cost and to improve quality of feed. The standard maintenance practices for feed pellet operation is derived by considering various practical parameters and given in section 3. The parameters in shop floor are always considerable for updating standard maintenance practices time to time. It must be easy to understand by the operators, technicians and maintenance team. It need not be the permanent procedure. There should be significant improvements if SMPs is updated.

\section{References}

[1] J. L. Maier, D. E., Watkins, B. A, and Behnke, K. C., "Effect of ingredients and proceesing parameters on pellet quality," in Poultry Science, vol. 78, pp. 1464-1471, 1999.

[2] R. Champion, "Pelleting and particle size reduction," Waterloo, Lowa. USA, 1997. 